\title{
Stenting of Right Ventricular Out Flow Tract: Analysis of 32 Cases from Catheterization Laboratory of a Paediatric Cardiac Centre
}

\author{
Nurun Nahar Fatema Begum¹, Nazmul Islam Bhuiyan², Ashfaque Ahemmed Khan²
}

\begin{abstract}
:
Introduction:The objectives of the present study are to describe the institutional experience, technical aspects and outcome of right ventricular outflow tract (RVOT) stenting in Tetralogy of Fallot type lesions as the initial palliation in a Bangladeshi centre.

Methods: This is a retrospective, single-center study of nonrandomized, consecutive 32 patients over a 12-year period. Selected patients underwent cardiac catheterization for implanting a stent into an obstructed RVOT to improve pulmonary blood flow.Statistical data analysis was performed using SPSS 20.

Results: Thirty cases had stenting in RVOT and two cases were postponed. Median age was 8.1 (3-40) months, median weight was $4.8(3.3-11.4) \mathrm{kg}$, median procedure time was 65 (26-210) minutes and fluoroscopy time was 16 (10-75) minutes.Stents were implanted through $5 \mathrm{~F}$ Judkins
\end{abstract}

coronary guide catheter and $5 \mathrm{~F}$ or $6 \mathrm{~F}$ delivery sheath of ADOIl device. Median stent diameter was 6 (4-7) mm. Stent length varies from $12-22 \mathrm{~mm}$ with median $14 \mathrm{~mm}$. Oxygen saturation of the patients increased from median 60 (30 $75) \%$ to $91(85-98) \%$. In one patient stent was embolized to aorta and was fixed to descending aorta. Two cases were postponed for short infundibular length. One patient died from non cardiac cause two months after palliation. No procedure related mortality recorded.

Conclusion: Right ventricular outflow tract stenting is a good option of palliation for small babies with reduced pulmonary blood flow. In our setting we did most of the palliation to offer better quality of life who could not afford surgery or who was detected late.

Keywords: Right ventricular out flow tract; stenting; Tetralogy of Fallot.

(Bangladesh Heart Journal 2020; 35(1): 1-5)

Introduction:

Primary repair of Tetralogy of Fallot (TOF) or ToF like lesion with confluent pulmonary arteries is the standard treatment protocol in many institutions. Right ventricular out flow stenting are used to palliate a wide variety of congenital heart lesions with Tetralogy of Fallot physiology 1 . This kind of palliation in patient with small pulmonary arteries with or without association of comorbidities, low body weight

1. Professor \& Head of the Dept. of Paediatric Cardiology, $\mathrm{CMH}$ Dhaka, Bangladesh.

2. Associate Professor, Dept. of Paediatric Cardiology, $\mathrm{CMH}$ Dhaka, Bangladesh.

Address of Correspondence: Professor Nurun Nahar Fatema Begum, Brigadier General, Department of Paediatric Cardiology, CMH Dhaka. Mobile: +88 01819239021, E mail: colfatema@hotmail.com relieves cyanosis and defers surgery for sometime. This in turn allows somatic growth and growth of pulmonary arteries with good opportunities for future surgery and its outcome $^{2}$. RVOT stenting is an effective bridging procedure from palliation to definitive surgery thus avoids mortalities from early surgeries like total repair or Blalock Taussig shunt (BT shunt) ${ }^{3-5}$.

\section{Methodology:}

Retrospective review of the patients clinical records, Echo report, Angiography report, OPD follow up notes were performed from Jan 2007 to September 2019. All patients with TOF physiology who had RVOT stenting attempt were enrolled in the study group from catheterization laboratory 
data base. Total thirty two cases were isolated from records. Two of them were postponed after trial in catheterization laboratory.

All RVOT stenting procedures were performed under general anesthesia and mechanical ventilation. All patients received 50 IU Heparin/

$\mathrm{kg}$ and standard antibiotic prophylaxis. After getting the venous access, theprocedure of stenting in RVOT includes(1) Right ventriculography in antero posterior (AP) and lateral view and measurement of length of RVOT and diameter in systole and diastole to decide stent length and diameter(2) To look for any supravalvular stenosis. If present, then stenting across pulmonary annulus and beyond stenotic arAeawas considered. (3) Aortogram to look for close proximity of RVOT to coronary arteries (4) Placement of exchange wire to branch pulmonary artery. (5) Placement of long sheath or guide catheter over the wire (6) Placement of stent with side arms injection for checking position of stent. The premounted stent over a balloon was inflated manually with indeflator up to the prescribed nominal pressure i.e. 8 atm for GENESIS ${ }^{\mathrm{TM}}$,Express ${ }^{\circledR}$ LD and NEFRO peripheral stent; 9 atm for Gazelle ${ }^{\circledR}$ and Liberte' ${ }^{\circledR}$ coronary stent. In one case three coronary stents were used. In another case two Express ${ }^{\circledR}$ LD vascular stents were used to cover the whole infundibulum. In one case first stent was embolized to right pulmonary artery and inflated there with balloon. Another RVOT stent was deployed again. Patients were routinely extubated on the table and transferred back to the ward. Patients who experienced an increase of oxygen saturations in excess of $20 \%$ were commenced on twice daily diuretics. Aspirin (3-5 mg/kg) was commenced once the patient started feeding. This was maintained until complete repair with explantation of the stent.

Informed consent was obtained from the parents of each patents. Permission of the institutional ethical committee was obtained. After collection, data were compiled and analyzed in MS excel spread sheet. As this study was carried out on single variants, comparative analysis were not performed.

\section{Results:}

Thirty two patients underwent RVOT stenting. Two cases were postponed; one due to very short infundibulum and another due to embolization of stent to Aorta for short infundibulum. Age of most of the patients was from 3 months to 12 months $(65.65 \%)$. Some children of $>36$ month to 40 month $(6.25 \%)$ were in the series. They were untreated cases due to monetary constraint or late reporting.Median age was 8.1 months (Table I).

Table-I

Age distribution of patients $(N=32)$

\begin{tabular}{lcc}
\hline Age & Number & Percentage \\
\hline 03 Mo to 12 Month & 21 & $65.63 \%$ \\
$>12$ Mo to 36 Month & 9 & $28.12 \%$ \\
$>36$ Mo to 40 Month & 2 & $6.25 \%$ \\
\hline
\end{tabular}

Median age 8.1 months

Among 32 cases, $62.5 \%$ were female (fig- 1 ) Tetralogy of Fallot was the main lesion in study cases $(56.25 \%)$, DORV, VSD, PS was present in $40.62 \%$ cases and complete AV canal defect, DORV, PS in $3.12 \%$ cases (Table-II). Weight of the patient ranged for 3-11 kg with median of $4.8 \mathrm{~kg}$ (Table-III). Most common type of stent used were GENESIS ${ }^{\mathrm{TM}}$ peripheral stent $(32.4 \%)$ followed by Boston scientific Express ${ }^{\circledR}$ LD stent $(24.3 \%)$ and NEFRO® peripheral stent (21.6\%) (Fig-II).

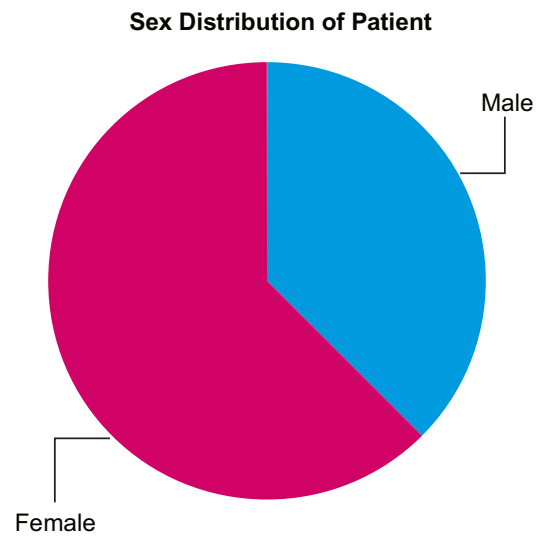

Fig.-1: Sex distribution of patients $(N=32)$

Out of 32 cases, 12 (37.50\%) were male and 20 (62.5\%) were female

Table-II

Disease type with TOF or ToF physiology cases $(N=32)$

\begin{tabular}{lcc}
\hline Disease type & Number & Percentage \\
\hline ToF & 18 & $56.25 \%$ \\
DORV, VSD, PS & 13 & $40.62 \%$ \\
AV Canal, DORV, PS & 01 & $3.12 \%$ \\
\hline
\end{tabular}

Note: TOF- Tetralogy of Fallot, DORV- Double outlet right ventricle, VSDVentricular septal defects, PS-Pulmonary stenosis, AV canalAtrioventricular canal 
Table-III

Weight distribution of patient at the time of stent implantation $(\mathrm{N}=32)$

\begin{tabular}{lcc}
\hline Weight in Kg & Number & Percentage \\
\hline $3-5 \mathrm{Kg}$ & 17 & $53.12 \%$ \\
$>5-11.4 \mathrm{Kg}$ & 15 & $46.85 \%$ \\
\hline
\end{tabular}

Median weight was $4.8 \mathrm{Kg}$

Type of stent used in patient

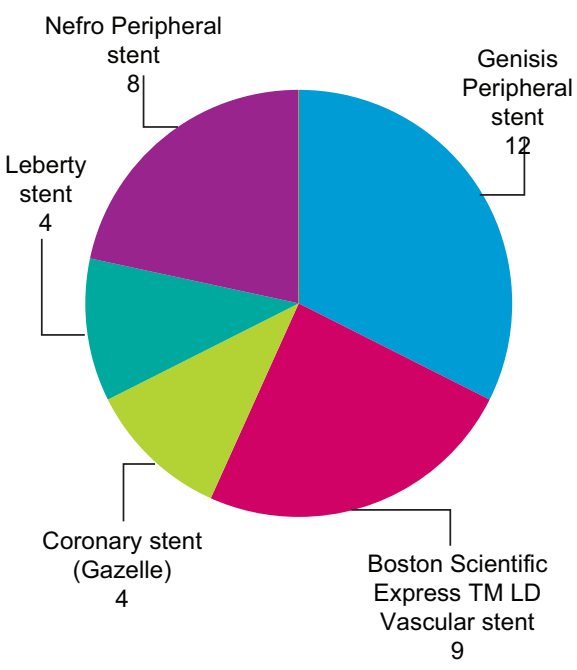

Multiple stents were used in 3 cases

Fig.-2: Type of stent used in patient $(N=32)$

Stent diameter varied for 4-7 $\mathrm{mm}$ and median was 6 $\mathrm{mm}$. stent length varied for $12-22 \mathrm{~mm}$ and median was $14 \mathrm{~mm}$. Stent diameter was decided from in fundibular Diameter at diastole (Table-IV). Procedure time varied from 26-210 munities. With experience of the cath lab team, procedure time was reduced. Fluoroscopy median time was 15 munities. Oxygen saturation varied for $30 \%$ $70 \%$ with median $66 \%$. Oxygen saturation after stenting varied from $85-98 \%$ with median $91 \%$ (Table- V).

Table-IV

Range and median of stent size, oxygen saturation and procedure time of Patients $(\mathrm{N}=32)$

\begin{tabular}{lcc}
\hline Variables & Range & Median \\
\hline Stent diameter & $4-7 \mathrm{~mm}$ & $6 \mathrm{~mm}$ \\
Stent Length & $12-22 \mathrm{~mm}$ & $14 \mathrm{~mm}$ \\
Procedure time & $26-210 \mathrm{~min}$ & $63 \mathrm{~min}$ \\
Fluoroscopy time & $10-75 \mathrm{~min}$ & $15 \mathrm{~min}$ \\
Oxygen saturation (Before stenting) & $30 \%-70 \%$ & $66 \%$ \\
Oxygen saturation (After stenting) & $85 \%-98 \%$ & $91 \%$ \\
\hline
\end{tabular}

Table $\mathrm{V}$ showed outcome of the patient. Stepping up of oxygen level above $85 \%$ was considered as good outcome and achieved in $93.75 \%$ cases. One case was postponed for very short infundibular length. Another postponed after embolization to Descending Aorta due to short infundibulum and embolized stent was positioned to abdominal aorta later. In another case first stent was embolized to RPA which was stationed there (Fig-III). There was no procedure related mortality.

Table-V

Outcome of patients $(N=32)$

\begin{tabular}{lcc}
\hline Variables & Number & Percentage \\
\hline Good (SPO2 > 85\%) & 30 & $93.75 \%$ \\
Postponed for short RVOT & 01 & $3.12 \%$ \\
Embolized to Aorta & 01 & $3.12 \%$ \\
Embolized to RPA & 01 & $3.12 \%$ \\
Procedure Related Death & 00 & $00 \%$ \\
\hline
\end{tabular}

\section{Discussion:}

Some infants with Tetralogy of Fallot like physiology are premature, low body weight, and have poor pulmonary artery anatomy, having non cardiacabnormalities etc and outcome of surgery is guarded. In our institution lack of money for costly cardiac surgery and lack of surgical facilities on young infant are additional factors. So right ventricular outflow tract stenting sparing pulmonary valve is a good option of bridging to aorto pulmoary shunt, or complete repair ${ }^{6-7}$. This procedure not only allowed somatic and pulmonary growth but also help to get rid from comorbidities ${ }^{8-9}$. In our institution, RVOT stenting is offered to get benefit for interim period with good quality of life and positive growth curve until they can manage cost of definitive surgery. It may be mentioned here that there is no health insurance policy for this kind of patient in our country. Cardiac surgery counterpart in our institution is still in their learning curve and they prefer to do surgery on a patient of TOF when they achieve 10 kilogram body weight. In most of the institute, elective TOF repair is performed at 6 month of age if pulmonary artery size is adequate by McGoon ratio or Nakata Index or by Z scoring. Important risk factor for early total repair is low body weight $(<2.5 \mathrm{~kg}$ ) prematurity ( $<37$ weeks), pulmonary artery hypoplasia (Z score <-2) and important non cardiac comorbidities. ${ }^{5}$ Although RVOT stenting is an accepted palliation for patients with TOF, consideration should be given to the anatomy for a safe placement of the stent especially when there is a deficient infundibular septum as in a doubly committed sub arterial VSD. ${ }^{10}$ RVOT stenting is contraindicated in situation 
where RVOT patency could not be established e.g. RVOT muscular atresia or nonconfluent central pulmonary arteries. Aortopulmonary shunt or ductal stent are ideal for such cases. ${ }^{11}$. There is no hard and fast rule for early repair versus bridge to complete repair by aortopulmonary shunt, arterial duct stenting or RVOT stenting or RVOT accentuation. ${ }^{12}$ Centers with good experience and outcome of early repair have identified low body weight, severe cyanosis, pulmonary atresiarather than stenosis, hypoplastic pulmonary arteries and non cardiac comorbidities as risk factor for mortality in these children. ${ }^{13-14} \mathrm{BT}$ shunt though very effective but it continues to carry a very high mortality and morbility. ${ }^{15}$ There is also chance of pulmonary artery distortion, stenosis and need for a separate surgical incision. ${ }^{16}$ RVOT stenting in Fallot-type lesions can be accomplished safely, with lower PICU admission rate, a shorter hospital length of stay and shorter duration of palliation until complete repair compared with mBTS palliation. ${ }^{17}$

Transcatheter intervention of congenital heart disease is getting access beyond the limit as outcome in most of the cases are good and mortality is negligible. Modern coronary intervention kits are suitable for use in newborn babies also. As a result, stenting of arterial duct and stenosed BT shunt has become a routine practice in many institutions. ${ }^{18-19}$ Stenting of right ventricular outflow tract was first attempted by Hausdorff and Gibbs and result were not good. ${ }^{20}$

Our first case of RVOT stenting was performed in a spelling child of $3 \mathrm{~kg}$ when all the available cardiac surgeons refused the case as she was very sick and was ICU bound since birth. ${ }^{21}$

In our series we preferred for surgical options in cases where body weight was reasonable and pulmonary anatomy were acceptable. But then we decided for RVOT stenting when patient failed to manage fund or surgeons refused the case. In $53.12 \%$ cases body weight of the patients were less than $5 \mathrm{~kg}$. After achieving significant skill, technique has now become popular in our centre and has become standard approach for patient with Fallot type physiology who is too young or too high risk for complete repair. Surgeons are also becoming comfortable to deal with stented RVOT during complete repair. ${ }^{22}$ Stenting across pulmonary valve annulus can be avoided in most of the patient which in turn leaves the opportunity to avoid transannulur patching at the time of repair. In babies less than $3.5 \mathrm{~kg}$ we used coronary stent (Liberte' ${ }^{\circledR}$ Boston scientific) and PALMAZ GENESIS ${ }^{\text {TM }}$ stent.In older groups, NEFRO $\circledast$ peripheral stent, Boston scientific Express $\AA^{\circledR}$ LD vascular stents were used.

In syndromic case, redilatationof stent may be required and stent should be selected accordingly. RVOT stenting in severe form of TOF physiology cases with late presentation may reduce perioperative death from reperfusion injury by gradual increment of pulmonary blood flow.All transcatheter procedures of RVOT stenting were done utilizing off-label stents and accessories. Surgeons, interventionalists, and engineers will need tocollaborate to establish new purpose-built stent or devicesthat are more effective. ${ }^{23}$

\section{Conclusion:}

Right ventricular outflow tract stenting has revolutionized the management approach of Fallot physiology cases especially in country like ours where presentation of patient is late and most of the patientsare not solvent to afford surgery. At the same time surgery for infants and high risk cases are not possible in most of the centers.

\section{Reference:}

1. Sandoval JP, Chaturvedi RR, Benson L, Morgan G, Asdell GV, Honjo O et al. Right Ventricular Outflow Tract Stenting in Tetralogy of Fallot Infants With Risk Factors for Early Primary Repair. Circ Cardiovasc Interv.2016;9(12):e003979.doi:10.1161/CIRC INTERVENTIONS.116.003979.PMID: 27965298.

2. Al Habib HF, Jacobs JP, Mavroudis C, Tchervenkov $\mathrm{Cl}$, O'Brien SM, Mohammadi S, et al.Contemporary patterns of management of tetralogy of Fallot: data from the Society of Thoracic Surgeons Database. AnnThorac Surg. 2010; 90:813-819

3. Arsdell GSV, Maharaj GS, Tom J, Rao VK, Coles JG, Freedom RM et al. What is the optimal age for repair of tetralogy of Fallot? Circulation. 2000; 102(19suppl 3):III123-III129.

4. Kirsch RE, Glatz AC, Gaynor JW, Nicolson SC, Spray TL, et al. Results of elective repair at 6 months or younger in 277 patients with tetralogy of Fallot: a 14-year experience at a single center. JThoracCardiovasc Surg. 2014; 147:713-717.

5. Sandoval JP, Chaturvedi RR, Benson L, Morgan G, Van Arsdell G, Honjo O, et al. Right Ventricular Outflow Tract Stenting in Tetralogy of Fallot Infants With Risk Factors for Early Primary Repair. Circ Cardiovasc Interv. 2016 Dec; 9(12): e003979. doi:10.1161/CIRCINTERVENTIONS.116.003979. PMID: 27965298. 
6. Kang SL, Benson L. Recent advances in cardiac catheterization for congenital heart disease. F1000Res. 2018;7:370. Published 2018 Mar 26. doi:10.12688/f1000research. 13021.1. PMID: 29636905; PMCID: PMC5871969.

7. Haas NA, Laser TK, Moysich A, Blanz U, Sandica E. Stenting of the right ventricular outflow tract in symptomatic neonatal tetralogy of Fallot. Cardiol Young. 2014;24(2):369-373.

8. Quandt D, Ramchandani B, Stickley J, Mehta C, Bhole V, Barron DJ, et al. Stenting of the Right Ventricular Outflow Tract Promotes Better Pulmonary Arterial Growth Compared With Modified Blalock-Taussig Shunt Palliation in Tetralogy of Fallot-Type Lesions. JACC Cardiovasc Interv. 2017; 10(17):1774-1784.

9. McGovern E, Morgan CT, Oslizlok P, Kenny D, Walsh KP, McMahon CJ. Transcatheter stenting of the rightventricular outflow tract augments pulmonary arterial growth in symptomaticinfants with right ventricular outflow tract obstruction and hypercyanoticspells. Cardiol Young. 2016; 26(7): 1260-5.

10. Lee J, Sivalingam S, Alwi M. Stenting of right ventricular outflow tract in Tetralogy of Fallot with subarterial ventricular septal defect: A word of caution. Ann Pediatr Cardiol. 2017 SepDec;10(3):281-283.

11. Gladman G, McCrindle BW, Williams WG, Freedom RM, Benson LN. The modified Blalock-Taussig shunt: clinical impact and morbidity in Fallot's tetralogy in the current era.JThoracCardiovasc Surg. 1997; 114:25-30.

12. Stumper O, Ramchandani B, Noonan P, Mehta C, Bhole V, Reinhardt Z, et al. Stenting of the right ventricular outflow tract.Heart. 2013; 99:1603-1608

13. Pigula FA, Khalil PN, Mayer JE, del Nido PJ, Jonas RA. Repair of tetralogy of Fallot in neonates and young infants. Circulation.1999; 100(19suppl): II157-II161.

14. Castleberry CD, Gudausky TM, Berger S, Tweddell JS, Pelech AN. Stenting of the right ventricular outflow tract in the high-risk infant with cyanotic tetralogy of Fallot. PediatrCardiol. 2014;35(3): 423-30.

15. Hirsch JC, Mosca RS, Bove EL. Complete repair of tetralogy of Fallot in the neonate: results in the modern era. Ann Surg. 2000;232:508-514.

16. Petrucci O, O'Brien SM, Jacobs ML, Jacobs JP, Manning PB, EghtesadyP. Risk factors for mortality and morbidity after the neonatal Blalock-Taussig shunt procedure. AnnThorac Surg. 2011; 92:642651

17. Quandt D, Ramchandani B, Penford G, Stickley J, Bhole V, Mehta C, et al. Right ventricular outflow tract stent versus BT shunt palliation in Tetralogy of Fallot. Heart. 2017;103(24):1985-1991.

18. Alwi M. Stenting the ductusarteriosus: case selection, technique and possible complications. Ann Pediatric Cardiol. 2008;1:38-45.

19. Vaughn GR, Moore JW, Mallula KK, Lamberti JJ, ElSaid HG. Transcatheter stenting of the systemicto-pulmonary artery shunt: A 7-year experience from a single tertiary center. Catheter Cardiovasc Interv. 2015;86(3):454-462.

20. Gibbs JL, Uzun O, Blackburn ME, Parsons JM, Dickinson DF. Right ventricular outflow stent implantation: an alternative to palliative surgical relief of infundibular pulmonary stenosis. Heart. 1997 Feb;77(2):176-9.

21. NN Fatema. Stenting of Right Ventricular Outflow Tract in a case of DORV, VSD and severe Infundibular Stenosis. Bangladesh. Journal of cardiology. 2014; Vol: 6 (1-2), 679-681.

22. Barron DJ, Ramchandani B, Murala J, Stumper O, De Giovanni JV, Jones TJ, et al. Surgery following primary right ventricular outflow tract stenting for Fallot's tetralogy and variants: rehabilitation of small pulmonary arteries. Eur J Cardiothorac Surg. 2013;44(4):656-62.

23. Van Arsdell GS, Levi DS. Neonatal Tetralogy Staged Versus Complete Repair: Is it Time to Rethink Neonatal Tetralogy?. J Am Coll Cardiol. 2019; 74(12):1580-1581. 